\title{
Feasibility Study of a National Web-Based GIS Application to Assess the Risk of Pesticide Drift in the U.S.
}

\author{
Faye Anderson, Najla N. J. Al-Thani \\ Independent Scholars, Houston, TX, USA \\ Email: andersonfaye7@gmail.com
}

Received 17 August 2015; accepted 8 September 2015; published 11 September 2015

Copyright (C) 2015 by authors and Scientific Research Publishing Inc.

This work is licensed under the Creative Commons Attribution International License (CC BY). http://creativecommons.org/licenses/by/4.0/

(c) (i) Open Access

\section{Abstract}

Agricultural pollution is a major issue in the United States (U.S.) and the world. Biotic and abiotic farming byproducts adversely affect the ecosystem and human health. While pesticides and fertilizers are the primary sources of agricultural pollution, organic agriculture can help remediate the negative effects on humans and the ecosystem. However, many factors like chemical drift can limit this advantage. This paper presents a feasibility study of a web-based (Geografic Information System) GIS application which can model and predict the areas affected by agricultural chemicals drift. Other applications exist with limited assumptions that make their outcomes far from reality. A root definition and a rich picture are developed as well as a Strengths Weaknesses Opportunities and Threats (SWOT) analysis. Because of the huge geographical context, data requirements and analyses requirements are expected to be massive. Nonetheless, despite the expected challenges, the advantages of the proposed application outweigh the risks.

\section{Keywords}

Risk of Chemical Drift, Organic Farming, Conventional Farming, Agricultural Pollution, U.S., GIS, Web-Based Application, SWOT, Root Definition, Rich Picture

\section{Introduction}

The increasing demand for organic agriculture has been driven by the rising demand on healthier nutrition [1], increasing concern of effects of accumulated chemicals in conventional crops, decreased biodiversity in conventional farms [2] and the increase in world population [3]. Organic farming is "a method of production, which places the highest emphasis on protecting and enhancing the environment and minimizing pollution” [4]. Unlike 
conventional farming, it avoids the use of artificial substances such as pesticides and chemical fertilizers, which are the primary sources of agricultural pollution. These two leach into and contaminate both surface water and groundwater, causing adverse health issues for plants, animals, humans and the environment [5] [6]. While organic farming can offset the contamination posed by conventional farming by increasing nutrient uptake and soil nitrogen, carbon and water levels, over-use of organic matter in organic farming has contributed to high ground water contamination, which can be managed by certain practices like crop rotation, soil aeration and timing of organic fertilizer application [7]-[9].

Although organic certification requirements can be lengthy, expensive and strict, it does not protect the organic crop or product from pesticide or herbicide drift from neighboring conventional farms. Organic production standards prohibit the use of artificial chemicals. Such drifts affect organic production in a very wider area and can consequently cause huge economic losses for the organic producer [10]. Figure 1 presents the change in total cropland area in the U.S. from 1945 through 2007 [11]. The severe drought of 2002 caused a loss of 34 million acres of cropland. This was accompanied by an increase in percentage of certified organic acreage of the total U.S. cropland (Figure 2) [12]. Despite the United States Environmental Protection Agency's (EPA) effort to

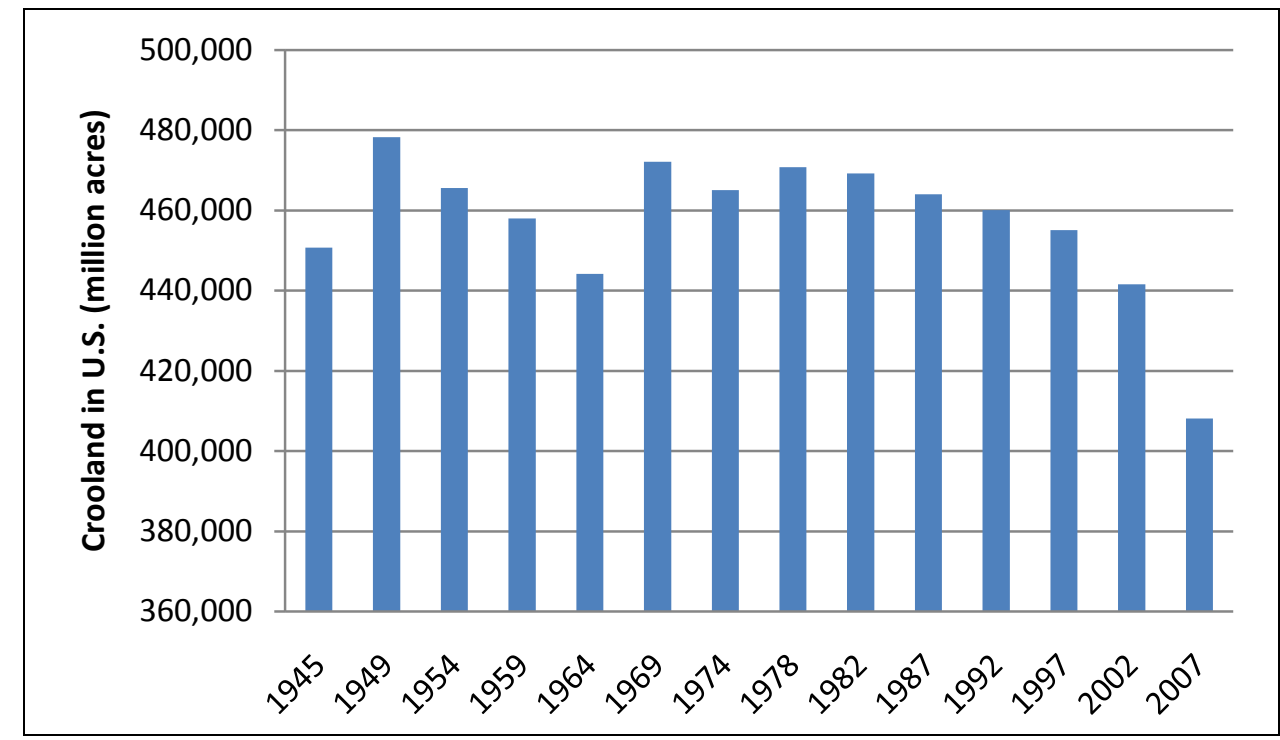

Figure 1. Cropland areas in the U.S., 1945-2007 [12].

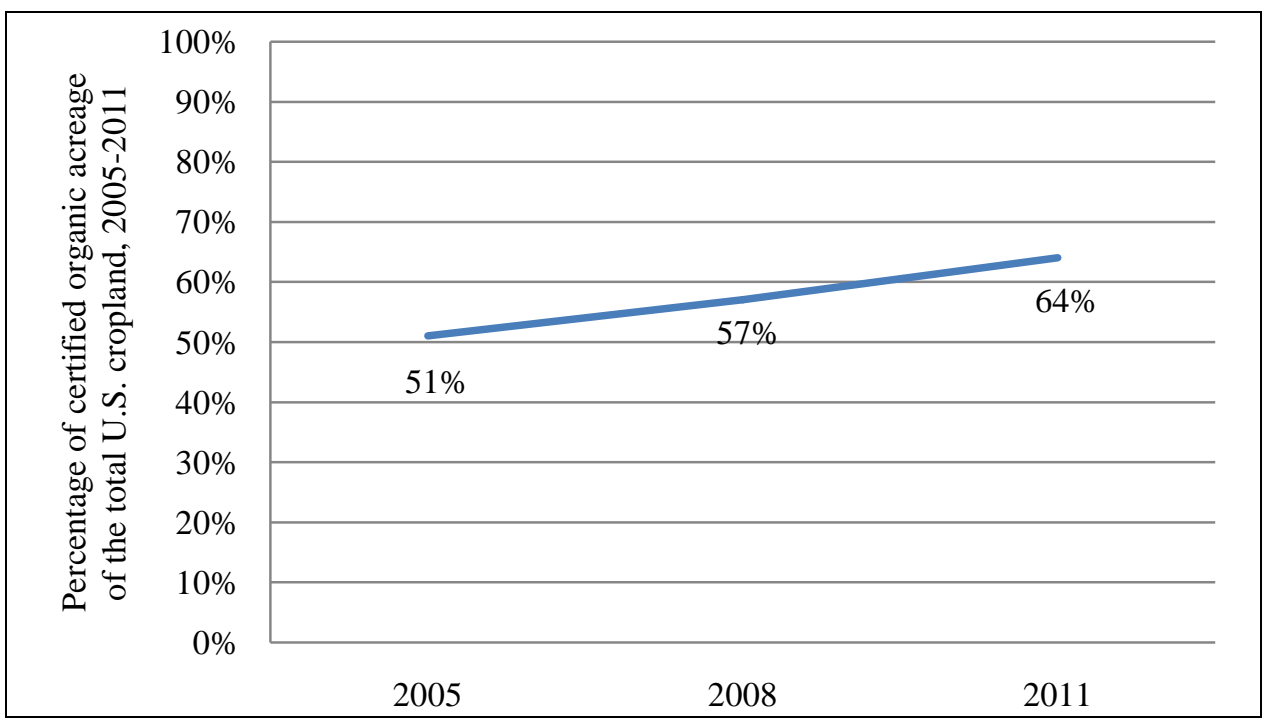

Figure 2. Percentage of certified organic acreage of the total U.S. cropland, 2005-2011 [13]. 
manage this problem, fertilizer and herbicide drift complaints are increasing annually [13], and the currently available similar applications have too many assumptions that make their results unrealistic and almost irrelevant [14]. This article presents a feasibility study of developing a comprehensive web-based GIS application to assess the risk of chemical drift in the U.S.

\section{Root Definition and Rich Picture}

The six scopes of root definition [15] are summarized in Table 1. The root definition of the proposed web-based GIS application is a system owned by the EPA and/or USDA, where areas affected by chemical drift are modelled and predicted reliably, because it is the right of the public to know about factors affecting their environment. The system runs under the challenge of lobbying conventional producers who use their rights to apply controlled chemicals. Figure 3 presents a rich picture for the issue that the proposed GIS-based application can address. The situation has six main stakeholders: conventional producers, organic producers, environmental protection organizations (EPO), USDA organic certification authority and chemical producers. Agricultural chemical producers support conventional farmers because they are the main customers for their products. Environmental protection agencies and organic producers have strenuous relationships with conventional producers for different reasons. EPOs need to producer risk assessments of the pesticides and their drifts, organic producers' profits are lost because of pesticide drifts and public health is negatively affected by it. The USDA organic certification authority penalizes organic producers by denying them the USDA organic seal if chemical traces are found in their produce, which costs organic producers a lot of money every year. EOPs produce reports and documents about their findings. Finally, conventional producers prefer spraying chemicals because this method is the fastest and most economical way to apply the chemicals.

\section{Strengths Weaknesses Opportunities and Threats (SWOT) Analysis}

SWOT analysis of the proposed application is given in Table 2. Internal factors are under strengths and weaknesses whereas external ones are under threats and opportunities. Strengths of the proposed application include

Table 1. The six scopes of the root definition.

\begin{tabular}{cl}
\hline Scope & \multicolumn{1}{c}{ Description } \\
\hline Client (whom?) & Organic farmers and the public \\
Actors (who?) & EPA and USDA \\
Transformation (what?) & Public health, maintenance or revocation of USDA organic seal \\
Worldview (Weltanshaung) (why?) & Protect the rights of organic consumers, the ecosystem and public health \\
Owners & EPA and/or USDA \\
Environment & $\begin{array}{l}\text { Expected opposition from conventional farmers and producers of governmentally-controlled fertil- } \\
\text { izers }\end{array}$ \\
\hline
\end{tabular}

Table 2. SWOT Analysis.

- Highly trained GIS developers are already on-board

- World-class researcher practitioners are already on-board

Internal

- Close relationships with EPA and both organic and conventional producers

- Technical and financial resources are available

- Excellent reputation of future application owners

- Available applications have limitations

External

- High interest in the application

- High demand for the application

- Boost public image
- Model is complex

- Missing data

- Data irregularities

- Opposition from conventional producers and agricultural chemical producers

- Long time of development and publishing

- Similar applications exist, with limiting assumptions

- Budget-cuts might affect the resources available for modelling and developing the new application 


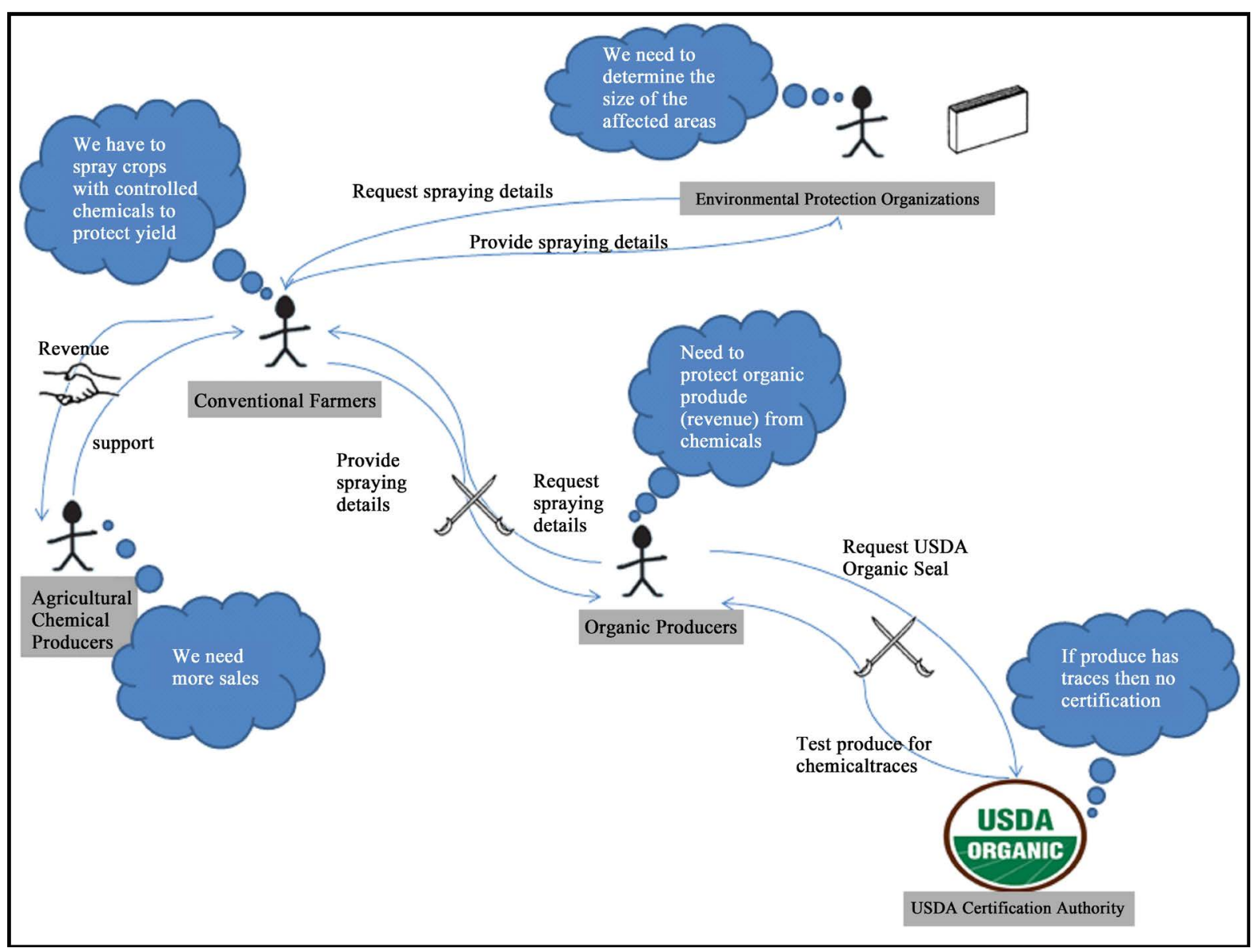

Figure 3. Rich picture of the problem that can be addressed by the proposed application.

the availability of highly trained GIS developers as well as research practitioners who have extensive expertise on the subject, and credibility. Weaknesses include the high complexity of the model and the huge data requirements. Opportunities include the gap that available applications cannot fill, profits for organic producers and increased environmental protection. Finally, threats include opposition from conventional producers and agricultural chemical makers.

\section{Data Requirements and Analyses}

The core of the proposed application is spatially and temporally linked to chemical spraying. Therefore, studying the geography of the U.S. is inevitable to the success of the project. The geography of the U.S. varies because of its huge area. Likewise, its climate represents a huge spectrum of ranges, varying from tropical rainforests of Hawaii to subarctic tundra of Alaska. This geographical context adds to the complexity of the application because huge amounts of spatial and temporal data are required. Analyses pertinent to spatial data face challenges like missing information, inconsistencies of classification, use of different aggregation levels, spatial data gaps and different time references [16].

\section{Implementation Plan}

A prototype is recommended to test the effectiveness of the developed model, ease of use and accessibility. Testing should start with collection of all relevant data. After data collection, integration and management processes are in place, the application should be tested for functionality. A web-based application is cost effective, guarantees high accessibility and interoperability. It also makes the application easy to customize and easier to use. Finally, it enhances the security capabilities [17]. 


\section{Conclusion}

Assessing the risks of chemical drifts in the U.S. needs a comprehensive web-based GIS application that can help the stakeholders especially the public understand the size of the issue. Although application is complicated, multi-dimensional in nature and costly, having it is necessary for public health.

\section{References}

[1] Wier, M. and Anderson, L.M. (2003) Demand for Organic Foods-Attitudes, Values and Purchasing Behaviors. Newsletter from Danish Research Center Farming, 2, 1-3.

[2] Wilson, J.D., Whittingham, M.J. and Bradbury, R.B. (2005) The Management of Crop Structure: A General Approach to Reversing the Impacts of Agricultural Intensification on Birds? Ibis, 147, 453-463. http://dx.doi.org/10.1111/j.1474-919x.2005.00440.x

[3] Gabriel, D., Carver, S.J., Durham, H., Kunin, W.E., Palmer, R.C., Sait, S.M., Stagl, S. and Benton, T.G. (2009) The Spatial Aggregation of Organic Farming in England and Its Underlying Environmental Correlates. Journal of Applied Ecology, 46, 323-333. http://dx.doi.org/10.1111/j.1365-2664.2009.01624.x

[4] Lichtfouse, E. (2009) Sociology, Organic Farming, Climate Change and Soil Science. Springer, Dordrecht.

[5] Ongley, E.D. (996) Control of Water Pollution from Agriculture. FAO Irrigation and Drainage Paper No. 55, FAO, Rome.

[6] Convey, G.R. and Pretty, J.N. (988) Fertilizer Risks in the Developing Countries: A Review. International Institute for Environment and Development, London.

[7] Dahan, O., Babad, A., Lazarovitch, N., Russak, E.E. and Kurtzman, D. (2013) Nitrate Leaching from Intensive Organic Farms to Groundwater. Hydrology and Earth System Sciences Discussions, 10, 9915. http://dx.doi.org/10.5194/hessd-10-9915-2013

[8] Jeffords, J.M. (2011) Effects of Organic Farming on Water Quality. https://www.uvm.edu/ vlrs/Environment/organic\%20farming\%20and\%20lake\%20pollution.pdf

[9] Ignazi, J.C. (1993) Prevention of Water Pollution by Agriculture and Related Activities. Proceedings of the FAO Expert Consultation, Water Report 1, 247-261.

[10] Maynard, E., Overstreet, B. and Riddle, J. (2011) Watch out for: Pesticide Drift and Organic Production. https://www.extension.purdue.edu/extmedia/ho/dw-1-w.pdf

[11] Economic Research Service (ERS) (2014) Major Land Uses. http://www.ers.usda.gov/data-products/major-land-uses.aspx

[12] Economic Research Service (ERS) (2013) Organic Production. http://www.ers.usda.gov/data-products/organic-production.aspx

[13] EPA (2015) Reducing Pesticide Drift. http://www2.epa.gov/reducing-pesticide-drift

[14] Lee, E.H., Burdick, C.A. and Olszyk, D.M. (2005) GIS-Based Risk Assessment of Pesticide Drift Case Study: Fresno County. http://www.epa.gov/wed/pages/publications/authored/EPA600R-05029PesticideDriftLee.pdf

[15] Petch, J. and Reeve, D.E. (1999) GIS, Organisations and People: A Socio-Technical Approach. CRC Press, Boca Raton.

[16] Mennecke, B.E. and West, L.A. (2001) Geographic Information Systems in Developing Countries: Issues in Data Collection, Management, and Use. The Journal of Global Information Management, 9, 45-55. http://dx.doi.org/10.4018/jgim.2001100103

[17] Lazakidou, A.A. (2009) Web-Based Applications in Healthcare and Biomedicine. Springer Science \& Business Media, New York. 